\title{
REFLEXÕES SOBRE A LEI AMAPAENSE DE CIÊNCIA, TECNOLOGIA E INOVAÇÃO: TENSÕES ENTRE TEXTO E CONTEXTO
}

\section{Linara Oeiras Assunção ${ }^{1}$}

\section{RESUMO:}

O estudo traz reflexões sobre a Lei estadual $n^{\circ}$ 2.333/2018, lei amapaense de ciência, tecnologia e inovação. Questiona: o contexto amapaense foi considerado no texto da Lei estadual $\mathrm{n}^{\mathrm{o}}$ 2.333/2018? A abordagem é qualitativa, compreensiva e utiliza pesquisa bibliográfica e documental. Trabalha com argumentos de legisprudência e legística. Narra o caso da empresa Natura e o acesso ao breu branco na Reserva de Desenvolvimento Sustentável do Rio Iratapuru-AP para demonstrar os prejuízos de ações legislativas descontextualizadas. A hipótese é de que a Lei estadual $n^{\circ} 2.333 / 2018$ não considerou o contexto socioambiental do estado e não foi fruto de debate plural.

Palavras-Chave: Ciência, Tecnologia e Inovação; Amapá; Lei Estadual Nº 2.333/2018.

\section{REFLECTIONS ABOUT AMAPÁ STATE LAW OF SCIENCE, TECHNOLOGY AND INNOVATION: TENSIONS BETWEEN TEXT AND CONTEXT}

\begin{abstract}
:
The study reflections about State Law no 2.333/2018, Amapá state law of science, technology and innovation. Question: was the Amapá context considered in the text of state law $\mathrm{n}^{\circ}$ 2.333/2018? The approach is qualitative, comprehensive and uses bibliographic and documentary research. It works with arguments of legisprudence and legistic. The case of the company Natura and the access to protium pallidum in the Sustainable Development Reserve of Rio Iratapuru-AP is described to demonstrate the damage of decontextualized legislative actions. The hypothesis is that state law $\mathrm{n}^{\circ} 2.333 / 2018$ did not consider the state's socioenvironmental context and was not the result of plural discussion.
\end{abstract}

Keywords: Science, Technology and Innovation; Amapá; State Law No 2.333/2018.

\section{INTRODUÇÃO}

As políticas de ciência, tecnologia e inovação (CT\&I) no mundo têm sido orientadas a buscar soluções para grandes desafios sociais, ambientais e econômicos. Diversas iniciativas direcionadas para o enfrentamento da mudança do clima e do uso mais sustentável dos recursos naturais, por exemplo, estão ancoradas em resultados decorrentes do

\footnotetext{
${ }^{1}$ Professora Adjunta no Curso de Direito da Universidade Federal do Amapá (UNIFAP). Professora Colaboradora no Mestrado Profissional em Estudos de Fronteira da Universidade Federal do Amapá (UNIFAP). Doutora em Direito pela Universidade Federal de Minas Gerais (UFMG). Mestre em Direito Ambiental e Políticas Públicas pela Universidade Federal do Amapá (UNIFAP). Macapá-AP. Brasil. lioeiras@ hotmail.com
} 
desenvolvimento científico e tecnológico. Da mesma forma, as estratégias para o aumento da competitividade econômica das nações estão fortemente relacionadas com as estratégias de avanço da inovação.

Contudo, para que se enfrentem esses desafios as políticas de CT\&I devem operar em um ambiente normativo claro e confiável. O desenvolvimento sempre vai abarcar a compreensão do direito pelos seus operadores: de como agir para efetivar o acesso dos cidadãos aos diversos bens. $\mathrm{O}$ oposto, a incompreensão por parte desses operadores, pode gerar um risco para o êxito das políticas públicas ou mesmo um obstáculo para a efetivação de direitos.

Para Coutinho e Mouallem (2015), a capacidade de um país gerar inovação demanda um complexo arranjo institucional no qual a ação governamental não apenas não pode ser dispensada, como se mostra decisiva para o desempenho das empresas ou firmas inovadoras, desde as grandes às pequenas. O Estado não é o agente diretamente responsável pela inovação, mas sem ele não é possível reunir as condições institucionais para ela ocorra. A inovação é, por isso, resultado da habilidade de a política pública estruturar arranjos capazes de induzir as empresas a investir em inovação e estimular a interação entre elas, as universidades e o próprio Estado (a hélice tripla ${ }^{2}$ ).

No Brasil, ao Poder Legislativo compete estabelecer normas que regulem e facilitem o pleno desenvolvimento das atividades de CT\&I. Diversas leis que viabilizam o funcionamento do SNCTI dependem de apreciação e aprovação do Congresso Nacional e das respectivas Assembleias Estaduais. Compete também ao Legislativo o acompanhamento, a fiscalização e o controle das políticas governamentais (MCTI, 2016).

Ocorre que o sistema brasileiro conta com um nada desprezível arcabouço jurídico resultante, historicamente, do acúmulo em "camadas geológicas" de instituições criadas em diferentes contextos e fases desde a segunda metade do século passado. E, assim, para Coutinho e Mouallem (2015), os mais significativos "gargalos à inovação" no Brasil não resultam tanto da falta de normas jurídicas, mas da visível dificuldade de fazê-las operar simultânea e coordenadamente.

Considerando a série de ações desencadeadas pelo poder público na busca pela

\footnotetext{
${ }^{2}$ Por esse modelo, a inovação não se projeta apenas em produtos e processos, mas no conhecimento gerado na/pela universidade, que interage com as perspectivas de desenvolvimento da indústria e recebe os recursos de fomento por meio de políticas públicas promovidas pelo Estado (ENGELMANN, 2010).
} 
estruturação da inovação no ordenamento jurídico brasileiro, muitos autores (como Grizendi, 2011), citam um conjunto de legislações como sendo o marco legal da inovação no Brasil. Desta feita, podemos perceber a inovação no país alicerçada, especialmente, sobre as seguintes normas: Lei $\mathrm{n}^{\circ}$ 8.248/1991, Lei de Informática e suas alterações; Lei $\mathrm{n}^{\circ}$ 10.973/2004, Lei de Inovação, regulamentada pelo Decreto $n^{0} 5.563 / 2005$, e suas alterações; Capítulo III da Lei n ${ }^{\circ} 11.196 / 2005$, Lei do Bem, regulamentado pelo Decreto $n^{\circ} 5.798 / 2006$, e suas alterações; Lei Complementar no 123/2006, Estatuto Nacional da Microempresa e da Empresa de Pequeno Porte, e suas alterações; Leis estaduais de inovação; Lei n 13.123/2015, que trata do acesso ao patrimônio genético, sobre a proteção e o acesso ao conhecimento tradicional associado e sobre a repartição de benefícios para conservação e uso sustentável da biodiversidade; A Emenda Constitucional no 85/2015, os arts. 218 e 219 da CF/88; e, a Lei no 13.243/2016 (novo marco legal de ciência, tecnologia e inovação).

Fica o destaque para o papel das lei estaduais de inovação dentro desse conjunto e mais diretamente a relevância de uma lei de inovação de qualidade para o desenvolvimento do Amapá.

Pois bem, no dia 25 de abril de 2018, o estado do Amapá publicou sua Lei de Ciência, Tecnologia e Inovação, que é resultante do Projeto de Lei n. 0006/2018-GEA, aprovado na Assembleia Legislativa no dia 04 de abril de 2018. A discussão acerca dos termos do lei foi curta e protagonizada por poucos atores.

Nesse sentido, a pesquisa parte da inquietação com as vozes que foram silenciadas no texto normativo da Lei estadual $n^{\circ}$ 2.333/2018, em face de uma realidade tão complexa como a do estado do Amapá que tem características peculiares. O território é aproximadamente $70 \%$ protegido por leis, englobando áreas de proteção ambiental, terras indígenas e quilombolas.

Abordar temas como desenvolvimento, ciência, tecnologia e inovação é tarefa árida. Então, questiona-se: o contexto amapaense foi considerado no texto da Lei estadual $n^{\circ}$ $2.333 / 2018 ?$

Para demonstrar a importância de uma relação adequada entre texto e contexto, a pesquisa narra o caso da empresa Natura Inovação e Tecnologia de Produtos Ltda. e o acesso ao protium pallidum (breu branco) na Reserva de Desenvolvimento Sustentável (RDS) do Rio Iratapuru-AP.

A discussão segue uma abordagem qualitativa, de cunho interpretativo, pautada em 
levantamento bibliográfico, estudo de caso e análise documental. Em sua perspectiva teóricometodológica trabalha com argumentos pautados na legisprudência e na legística, teorias ligadas à racionalidade e qualidade da legislação.

Apoia-se na hipótese de que a história do Amapá é recheada de casos, de experiências que poderiam ter sido ouvidas e aproveitadas para melhor contextualizar, adequando à realidade local e regional, a proposta legislativa aprovada. Ainda, acredita-se que a recente lei amapaense de CT\&I não foi fruto de um debate plural. O estado tem uma vocação socioambiental muito forte e esse viés tão importante não foi valorizado no texto legal.

\section{A IMPORTÂNCIA DAS LEIS ESTADUAIS DE INOVAÇÃO}

É salutar reconhecer que os Estados ao instituírem suas respectivas leis de inovação contribuem para fortalecer as áreas de pesquisa e produção de conhecimentos, fomentando a criação de novos ambientes, propícios à geração e absorção de inovações atuando como instrumentos de apoio às políticas industrial e tecnológica estaduais (PLAZA, 2011).

Até 2017, das 27 (vinte e sete) unidades federativas (26 estados e 1 Distrito Federal), 22 (vinte e dois) estados possuíam legislação interna de incentivo à inovação. E o Maranhão já tinha uma minuta em discussão. Dois estados da região Norte não possuíam um trabalho de elaboração legislativa publicizado em fase adiantada sobre o tema, a saber: Rondônia e Roraima. Na região Nordeste em situação semelhante tínhamos o Piauí e a Paraíba (ASSUNÇÃO, 2017).

Em razão da própria inserção deste trabalho, devemos lembrar que a região Norte é composta por 7 (sete) estados-membros: Acre, Amapá, Amazonas, Pará, Roraima, Rondônia e Tocantins e que possui a maior extensão das 5 (cinco) regiões brasileiras, aproximadamente 45\% do território nacional. Porém, a sua grandeza não está somente na dimensão geográfica, há neste ambiente uma riqueza incalculável em biodiversidade, o que a torna propícia ao desenvolvimento de pesquisas voltadas ao acesso da biodiversidade e geração de biotecnologias.

A Pesquisa de Inovação Tecnológica (PINTEC), realizada pelo Instituto Brasileiro de Geografia e Estatística (IBGE), mostrou que em 2014 a Região Norte gerou mais de R\$119 milhões em produtos ou processos que continham algum nível de inovação. Segundo a 
pesquisa, 1.493 empresas da região investiram mais de $\mathrm{R} \$ 2$ milhões para produção de novos produtos ou atividades internas de pesquisa e desenvolvimento (IBGE, 2016).

A respeito da relevância das leis estaduais, Bassalo (2012) pondera que a criação de uma ambiência apropriada à inovação passa a ser o grande diferencial entre aqueles que se desenvolvem de maneira sustentável e aqueles que apostam no crescimento econômico sem considerar possíveis consequências danosas ao ecossistema local.

Para a autora, os Sistemas Regionais de Inovação (SRI) voltados à estruturação, organização e operação de condições apropriadas à inovação são, portanto, considerados estratégias eficientes para o desenvolvimento de sociedades, principalmente, se alicerçados em relações de confiança e colaboração (BASSALO, 2012).

Desta feita, a ausência de leis de inovação de qualidade em estados da região Norte prejudica o desenvolvimento e o processo de conversão da biodiversidade presente nos territórios em riquezas.

No tocante às leis existentes, vale a pena frisar que as leis de inovação estaduais derivaram, em grande medida, da Lei federal no 10.973/2004, Lei de Inovação, transpondo, assim, para o ambiente estadual, os preceitos da lei federal, apresentando poucos pontos com peculiaridades regionais, locais, ou seja, agregando poucas novidades (GRIZENDI, 2011).

A Revista de audiências públicas do Senado Federal, Em Discussão!, em matéria publicada em setembro/2002, enfatizou que a edição de leis estaduais de inovação no Brasil é, de outra sorte, um dos aspectos centrais da expansão e consolidação do Sistema Nacional de Ciência, Tecnologia e Inovação (SNCTI), pois fortalecem a interação entre os atores desse sistema, que inclui governo federal e governos estaduais e agências de financiamento, universidades e empresas.

\section{O LEGADO DO PRIMEIRO CONTRATO DE ACESSO AOS RECURSOS DA BIODIVERSIDADE DO ESTADO DO AMAPÁ: O CASO DA EMPRESA NATURA E O ACESSO AO BREU BRANCO NA RESERVA DE DESENVOLVIMENTO SUSTENTÁVEL DO RIO IRATAPURU-AP}

Um fato ocorrido na comunidade da Reserva de Desenvolvimento Sustentável (RDS) do Rio Iratapuru, no Amapá, denuncia uma realidade típica da região Norte, na qual os recursos da biodiversidade, aplicados em ações de CT\&I, ainda não conseguem se converter 
em riquezas e em desenvolvimento local.

À época da formalização do contrato de acesso aos recursos da biodiversidade entre a comunidade da RDS e a empresa Natura Inovação e Tecnologia de Produtos Ltda., o Amapá já possuía uma lei de proteção à biodiversidade, ocorre que esta não dialogava, e ainda não dialoga, adequadamente com o ordenamento federal, tampouco era (re)conhecida pelos envolvidos.

A RDS do Rio Iratapuru ${ }^{3}$ é uma unidade de conservação de uso sustentável. Foi

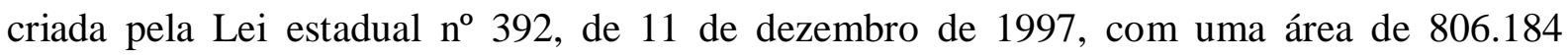
hectares, distribuídos nos territórios dos Municípios de Laranjal do Jari, Pedra Branca do Amapari e Mazagão. É gerida pela Secretaria de Estado do Meio Ambiente do Amapá (SEMA) (AMAPÁ ECO CAMPING, 2017).

A proteção da unidade é favorecida pela dificuldade de acesso à área e pela presença de áreas protegidas em seu entorno. Situada na porção sudoeste do Estado do Amapá, a RDS limita-se ao norte com a Terra Indígena Waiãpi; a leste e a nordeste com a Floresta Estadual do Amapá; a sudeste com o Projeto de Assentamento Agroextrativista do Maracá; ao sul com a Estação Ecológica do Jari; e a oeste com o rio Jari, divisa com o Estado do Pará (AMAPÁ ECO CAMPING, 2017).

O acesso a partir da capital do Estado, Macapá, é pela BR-156, num percurso de cerca de 270 quilômetros até o município de Laranjal do Jari. Deste ponto até a localidade chamada Porto Sabão, no município de Almeirim, no Estado do Pará, percorrem-se ainda aproximadamente 20 quilômetros. Deste local segue-se via fluvial por aproximadamente 15 quilômetros a montante pelo rio Jari (AMAPÁ ECO CAMPING, 2017).

A pressão antrópica sobre a área resulta de assentamentos no entorno e de garimpos clandestinos ao norte, nas cabeceiras de igarapés, dentro e fora da área, que faz o limite da reserva. Embora não existam moradores na unidade, cerca de 150 famílias residentes no entorno, distribuídas em 7 (sete) comunidades, utilizam a RDS para atividades extrativistas, principalmente coleta de castanha-do-brasil (bertholletia excelsa) e breu branco (protium

\footnotetext{
${ }^{3} \mathrm{O}$ nome Iratapuru é derivado do pássaro, de nome muito semelhante, Uirapuru (Cyphorhinus aradus). O Uirapuru é uma ave nativa da Amazônia e seu nome tem origem no termo do Tupi-guarani, wirapuru. Esse pássaro é cercado de lendas graças ao seu canto, considerado um dos mais belos do mundo. A espécie é territorialista e defende seu território de forma bem agressiva, utilizando o canto como forma de intimidar invasores. A comunidade que trabalha com a extração de castanha-do-Brasil na região costuma ouvir bastante o canto do Uirapuru e deu ao rio e, consequentemente, à Reserva de Desenvolvimento Sustentável, uma versão adaptada do nome do pássaro (WWF BRASIL, 2010).
} 
pallidum). Além disso, essa população pratica a caça e a pesca de subsistência no interior da reserva (AMAPÁ ECO CAMPING, 2017).

Foi nesse cenário que a empresa Natura, no início dos anos 2000, acessou o componente genético breu branco (protium pallidum), usando como base para as pesquisas o conhecimento tradicional da comunidade da Vila São Francisco do Iratapuru (RIBEIRO, 2016).

Para compreender a utilidade do breu branco, Ribeiro (2016) explica que se trata de uma resina de cor acinzentada, oleosa e amorfa retirada dos troncos da árvore de breu, também chamada de almácega ou almecegueira, de maneira similar à seringa (borracha). Após sua extração e secagem a resina torna-se endurecida e extremamente inflamável, usada com frequência para produzir fogo na mata. $\mathrm{O}$ breu exala, quando em brasas, um odor muito agradável, servindo também como defumador e incenso. Sua principal função aos castanheiros, no entanto, é a de brear canoa ${ }^{4}$, considerando que são exímios fazedores de embarcações (RIBEIRO, 2016).

Cabe esclarecer que as primeiras investidas da empresa Natura na comunidade começaram nos anos 2000 e 2001 com a retirada de amostras de breu branco por uma empresa parceira, a IFF Essências e Fragrâncias Ltda. Nesse período, testes e pesquisas foram realizadas, as quais consideraram promissor o uso do breu branco na fabricação de perfumaria fina (RIBEIRO, 2016).

Já em 2002, a Natura Cosméticos, por meio de outra empresa parceira, a Cognis do Brasil, comprou uma pequena quantidade de óleo de castanha do Brasil diretamente da comunidade São Francisco do Iratapuru. Àquela altura estavam sendo realizados mais testes em laboratório para verificar a eficiência de outros recursos além do breu branco (protium heptaphyllum), como a castanha do Brasil (bertholletia excelsa) e a copaíba (copaifera landesdorffi).

No ano seguinte, 2003, a Natura procurou novamente a comunidade do Iratapuru com a intenção de comprar uma grande quantidade de breu branco, visando ao lançamento de um perfume com a essência ainda naquele ano. Contudo, destaca Ribeiro (2016), raras vezes os castanheiros da comunidade do Iratapuru haviam comercializado o breu branco e sem

\footnotetext{
${ }^{4} \mathrm{O}$ termo indica uma maneira de calafetar as embarcações. Os castanheiros constroem barcos e batelões para navegar e transportar as castanhas pelos rios, após sua produção artesanal, utilizam essa resina para impermeabilizar as juntas dos barcos, impedindo, assim, a entrada de água e vazamentos durante as navegações e transporte de toneladas de castanhas (RIBEIRO, 2016, p. 4).
} 
muita experiência, requisitaram ao Governo do Estado do Amapá permissão para comercializarem com a Natura a resina do breu a $\mathrm{R} \$ 6,00$ o quilo ${ }^{5}$. Em paralelo a essa demanda, a Natura formalizava pedidos para comprar também o óleo da castanha do Brasil.

À vista disso, um pequeno grupo de castanheiros extraiu 300 quilos de breu branco e preparou-o para enviar à empresa. A venda foi considerada irregular pelo Governo do Estado sob a justificativa de inadequação quanto à legislação estadual de acesso à biodiversidade, que atribui à Secretaria de Estado do Meio Ambiente do Amapá (SEMA), a competência para autorizar ou não a bioprospecção ${ }^{6}$ por empresas e pesquisadores (RIBEIRO, 2016).

Em que pese a falta de experiência dos castanheiros na celebração de negócios, a ausência de domínio de aspectos jurídicos e legais e a clareza sobre a valorização de seus saberes e práticas tradicionais, em que pese a falta de compreensão da Natura acerca dos modos de vida florestais e das lógicas outras de negociação e vinculação típicos da região, onde contratos, papéis e documentos, em geral, têm pouco valor, o fato era que desde 1997 o Amapá possuía uma lei versando sobre a proteção ao acesso aos recursos da biodiversidade do Estado, a Lei $\mathrm{n}^{\circ}$ 0388, de 10 de dezembro de 1997, regulamentada pelo Decreto $\mathrm{n}^{\mathrm{o}} 1.624$, de 25 de junho de 1999 (RIBEIRO, 2016; COSTA, 2007) ${ }^{7}$.

Nesse contexto, de necessária adequação legal, como a Natura já havia previsto o lançamento do perfume do breu branco em 2003 e também já havia feito muitos investimentos nessa direção, a empresa acabou adquirindo a matéria-prima de que necessitava junto a outra comunidade, chamada Bituba e localizada no município vizinho à comunidade do Iratapuru, em Monte Dourado, pertencente ao Estado do Pará. Foi assim que, em 2003, a Natura pôde lançar 2 (dois) produtos que continham a essência do breu branco: o perfume do Brasil e a água de banho (RIBEIRO, 2016).

Mas o lançamento dos produtos e a compra da matéria-prima de outra comunidade

\footnotetext{
${ }^{5}$ A comunidade entendia que o breu branco não possuía um valor comercial tão interessante quanto a castanha do Brasil. No mercado local, os castanheiros costumavam vender o breu branco a R\$3,00 o quilo, sendo que a Natura estava disposta a pagar o dobro pelo insumo e para eles parecia um bom negócio (RIBEIRO, 2016).

${ }^{6}$ Bioprospecção pode ser entendida como pesquisa e exploração da biodiversidade de uma região, dos seus recursos genéticos e bioquímicos de valor comercial.

${ }^{7}$ Costa (2007) recorda que esta lei foi considerada um verdadeiro marco na história de defesa ambiental do Amapá, e também do Brasil, uma vez que naquela época inexistia legislação federal sobre o assunto. Dentre outras atribuições, a Lei $n^{\circ}$ 0388/97 trouxe a incumbência ao Poder Executivo de preservar a diversidade, a integridade e a utilização sustentável dos recursos genéticos localizados no Estado, além de fiscalizar as entidades dedicadas à pesquisa e manipulação de material genético, obedecendo-se aos seguintes princípios: a) a inalienabilidade dos direitos sobre a diversidade biogenética do Estado do Amapá; b) a participação das comunidades locais e dos povos indígenas, no acesso e nos benefícios econômicos e sociais decorrentes dos recursos biogenéticos; c) a proteção e o incentivo à diversidade cultural, valorizando-se as práticas das comunidades locais.
} 
não impediram uma comprovação inconteste: as amostras para realização de testes foram extraídas da RDS do Rio Iratapuru por castanheiros e moradores da Vila São Francisco do Iratapuru. Desse modo, independentemente da anuência da Natura, era obrigatória a regulamentação desse acesso junto ao Governo do Estado do Amapá e ao Conselho de Gestão do Patrimônio Genético (CGEN) ${ }^{8}$, instituído pela Medida Provisória no 2.186-16/2001.

Por tudo isso, a SEMA, que não havia sido consultada pela Natura sobre a retirada de material genético da RDS do Rio Iratapuru para fins de bioprospecção, embargou o acesso ao breu branco e realizou uma denúncia formal junto ao Ministério Público Federal. Após algumas pressões do Governo do Estado do Amapá e do CGEN, a Natura passou a considerar os instrumentos técnicos exigidos, como laudo antropológico, para que o acesso ao breu branco pudesse ocorrer dentro dos critérios fixados pela legislação vigente (RIBEIRO, 2016).

Inicialmente, as incursões para a regularização do acesso ao breu branco pela Natura desconsideraram o reconhecimento dos saberes tradicionais como passíveis de repartição de benefícios. Como consequência, as primícias da relação entre a Natura e a comunidade do Iratapuru foram marcadas por desentendimentos e conflitos entre os moradores da comunidade, representantes do Estado e funcionários da empresa (RIBEIRO, 2016).

Dito isso, somente em julho de 2004, o contrato foi formalizado para o acesso de utilização do patrimônio genético e repartição de benefícios entre a empresa Natura Inovação e Tecnologia de Produtos Ltda e a Cooperativa Mista dos Produtores e Extrativistas do Rio Iratapuru (COMARU), representando a comunidade. O governo do Estado do Amapá foi incluído como parte em um termo aditivo em dezembro de 2004 (SANTOS, 2008).

Esse contrato foi o primeiro do tipo firmado no Brasil entre uma população florestal e uma empresa privada ${ }^{9}$. Nele foram estabelecidos critérios específicos para a repartição de benefícios por meio da criação do denominado "Fundo Natura para o desenvolvimento das comunidades" (SANTOS, 2008, p. 15).

Conforme estabelecido em consequente convênio, para ter acesso ao Fundo a comunidade ficou incumbida do dever de elaborar um plano comunitário de desenvolvimento

\footnotetext{
${ }^{8}$ O CGEN foi criado visando à regulamentação das relações de troca que há muito já existiam entre populações amazônicas e empresas, biólogos, farmacêuticos e pesquisadores. O questionamento acerca das implicações éticas dessas relações iniciou um movimento de reconhecimento de direitos intelectuais e territoriais de populações locais. A formalização do CGEN, em 2001, como uma instância governamental responsável por essa regulamentação, reconfigurou os termos a partir dos quais essas trocas eram efetivadas (RIBEIRO, 2016).

${ }^{9} \mathrm{O}$ contrato foi assinado em 22 de julho de 2004, após quatro anos de negociação e muitas reuniões entre a empresa Natura, a SEMA, representando o estado do Amapá, e castanheiros do Iratapuru (SANTOS, 2008, p. 160).
} 
sustentável e de apresentar projetos com a aplicação dos valores depositados, prioritariamente, voltados à cadeia produtiva (RIBEIRO, 2016).

Santos (2008) recapitula que, quando o contrato foi assinado a comunidade do Iratapuru não tinha clareza das condições a partir das quais o fazia, entretanto, prevalecia a sensação geral de que esse acordo seria benéfico à comunidade e era visto de maneira positiva pelos castanheiros envolvidos na negociação.

Para que fique claro, a Natura e a comunidade São Francisco do Iratapuru passaram a manter, a partir de 2004, um contrato escrito, de prazo indeterminado e que visava regularizar o acesso ao patrimônio genético do breu branco. Das cláusulas desse contrato destaca-se seu objeto principal: o acesso ao patrimônio genético da resina breu branco, enquanto houver sua exploração comercial. Destaca-se ainda o compromisso de exclusividade com a comunidade, estando a Natura vetada de comprar o breu branco de outras fontes (SANTOS, 2008).

Ribeiro (2016) comenta que começava, então, o que viria a ser um longo relacionamento entre castanheiros habitantes do Iratapuru e a Natura Cosméticos (RIBEIRO, 2016). Isso porque em 2007, três anos depois, a Natura procurou a comunidade para firmar um novo contrato. $\mathrm{O}$ intuito era regularizar pendências do contrato anterior, esclarecer sobre os percentuais da receita líquida a serem depositados no Fundo ${ }^{10}$, colocar fim a algumas dificuldades que a própria empresa havia criado, como a gestão do Fundo, o processo de prestação de contas da comunidade e fiscalização acerca dos projetos exigidos e, especialmente, regularizar a repartição de benefícios pelos usos tradicionais do breu branco, ou seja, a inclusão no contrato dos conhecimentos tradicionais associados.

Passados mais três anos, em 2010, a Natura apresentou outra proposta de contrato para, enfim, repartir benefícios associados aos conhecimentos tradicionais da castanha do Brasil, apesar de comprar o óleo de castanha da comunidade desde do início dos anos 2000, como mencionado. Na assinatura deste contrato surgiu uma nova figura, a Associação da População Tradicional da Biodiversidade da Reserva de Desenvolvimento Sustentável do Rio Iratapuru (BIORIO), criada em maio de 2008 (RIBEIRO, 2016).

Note-se que esta associação composta por famílias que não participavam ativamente

\footnotetext{
10 Santos (2008) ressalta que em setembro de 2007 o Fundo contava com um valor estimado em R\$ 1.748.053,00, segundo informações da empresa em reuniões. Contudo, o valor exato nunca aparecia de maneira clara à comunidade, primeiro porque recebia depósitos cujos cálculos não dominavam, oscilando mês a mês, dependendo das vendas da Natura e, segundo porque a empresa refazia constantemente os cálculos, alterando-os em razão de erros. Em setembro do ano seguinte, 2008, os valores do Fundo ultrapassavam o valor de $\mathrm{R} \$$ $1.900 .000,00$.
} 
da COMARU foi criada para cuidar do social da comunidade, beneficiando todas as famílias, sem exceção. É fácil perceber, que surgiu, em larga medida, para solucionar conflitos internos entre as famílias do Iratapuru e como forma de distribuição de poderes na comunidade, em particular, no que se referia ao usufruto dos recursos provenientes da repartição de benefícios da Natura, um montante que se tornava cada vez mais expressivo (RIBEIRO, 2016).

Em razão do contrato com a BIORIO ficou avençado que os recursos que viessem do aumento da quantidade de óleo de castanha comprado pela Natura seriam geridos pela COMARU e os recursos advindos da repartição de benefícios pelos conhecimentos associados à extração e aos usos da castanha do Brasil, seriam geridos pela BIORIO (RIBEIRO, 2016).

Em todo esse percurso de negociações entre a Natura e a comunidade do Rio Iratapuru é fundamental ponderar que todas as ações, as propostas, foram impulsionadas, sobretudo, pelas decisões do CGEN acerca das solicitações de acesso realizadas.

De tudo que foi narrado, não podemos deixar de situar leitor do quanto as ações da Natura, da comunidade, do Governo do Estado do Amapá e do CGEN igualmente foram diretamente impactadas por inovações e alterações legislativas, por exemplo: em 2001 foi publicada a Medida Provisória $n^{\circ} 2.186-16^{11}$ (que dispunha sobre o acesso ao patrimônio genético, a proteção e o acesso ao conhecimento tradicional associado, a repartição de benefícios e o acesso à tecnologia e transferência de tecnologia para sua conservação e utilização), em 2004 entrou em vigor a Lei n 10.973 (Lei de Inovação) e em 2007 editou-se o Decreto $\mathrm{n}^{\circ}$ 6.040, contendo a Política Nacional de Desenvolvimento Sustentável dos Povos Indígenas e das Comunidades Tradicionais, no qual, finalmente, chegava-se a um consenso sobre o conceito normativo de comunidade tradicional ${ }^{12}$.

Verzola (2015) acentua que nesse meio tempo, de inovações e alterações legislativas, com o propósito de sanar questionamentos que se referiam à titularidade do conhecimento tradicional, caracterizado como direito difuso e coletivo, que dificultava a aplicação dos preceitos legais no aspecto prático na hipótese da celebração do contrato de acesso e

\footnotetext{
${ }^{11}$ Atualmente revogada pela Lei $\mathrm{n}^{\circ} 13.123 / 2015$.

${ }^{12}$ É emblemático na Região Norte o conflito ocorrido em 2005 envolvendo executivos da Natura, que visitaram o mercado Ver-o-Peso, em Belém-PA, e as ervateiras. As vendedoras de ervas do mercado acusaram os executivos de se apropriarem indevidamente de seus conhecimentos para a fabricação de perfumes, por meio de fotografias, filmagens e conversas. Inicialmente, questionava-se se poderiam as ervateiras serem reconhecidas como comunidade tradicional por estarem em uma área urbana. Mas o caso foi analisado pela Comissão de Bioética da Ordem dos Advogados do Brasil e pelos Ministérios Públicos Federal e Estadual, houve o reconhecimento como comunidade e o incidente resultou em reparações em forma de compensação. Para maiores detalhes, ver: Tanure e Patrus (2011).
} 
repartição de benefícios, a Casa Civil da Presidência da República chegou a realizar a Consulta Pública $n^{\circ}$ 02, em 14 de dezembro de 2006, elaborada pelo Ministério do Meio Ambiente. No entanto, "a aludida Consulta Pública sequer passou pelo Estado do Amapá, pioneiro na celebração de Contrato de Repartição de Benefícios na Reserva de Desenvolvimento Sustentável (RDS) do Iratapuru” (VERZOLA, 2015, p. 189). Ou seja, a população amapaense foi alijada daquele processo de consulta prévia que se referiu a uma problemática de legislação que vivenciava em concreto.

Este caso é emblemático e marcante para o contexto de desenvolvimento amapaense.

\section{A Lei AMAPAenSE de CIÊNCIA, TECNOLOGIA E INOVAÇÃo: TENSÕeS ENTRE TEXTO E CONTEXTO}

Como mencionado anteriormente, no dia 25 de abril de 2018, o estado do Amapá publicou sua Lei de Ciência, Tecnologia e Inovação, que é resultante do Projeto de Lei n. 0006/2018-GEA, aprovado na Assembleia Legislativa no dia 04 de abril de 2018. O Poder Executivo foi o autor do projeto e o movimento em prol da aprovação da lei foi capitaneado pela Secretaria de Estado de Ciência e Tecnologia (SETEC).

Em novembro de 2017, a Secretaria abriu em seu sítio eletrônico uma chamada pública para o preenchimento de formulário com vistas à participação popular na minuta do projeto de lei (PORTAL GOVERNO DO AMAPÁ, 2018). Apesar dessa possibilidade, nem antes e nem após a aprovação da lei houve prestação de contas do impacto da chamada pública (abrangência e número de contribuições), sobretudo em um estado como o Amapá onde o acesso à internet ainda é precário.

Além da chamada pública, a SETEC organizou 10 (dez) reuniões presenciais com os setores produtivos do estado (DIÁRIO DO AMAPÁ, 2017). No entanto, a divulgação do material produzido nessas reuniões também não foi publicizado. Ou seja, não houve a demonstração com clareza do caminho percorrido para a aprovação do texto.

A lei vigente, então, é composta de 45 (quarenta e cinco) artigos, com forte influência da Lei de Inovação (Lei n $\left.{ }^{\circ} 10.973 / 2004\right)$ e do Novo Marco Legal de CT\&I (Lei no 13.243/2016), e com pouquíssimas novidades no que diz respeito a valorização da realidade local e regional, ou seja, do contexto, seguindo uma tendência já alertada por Grizendi (2011). 
O legislador estadual amapaense não ousou, não criou. Há uma tentativa de criatividade quanto ao caráter de popularização de CT\&I, prevendo o prêmio "Inovação Amapaense". Contudo, da leitura da lei, uma constatação salta aos olhos: 19 (dezenove) dos 45 (quarenta e cinco) artigos, que constam no texto, contêm redação tirada de maneira direta ou com pouca alteração da Lei $n^{\circ} 10.973 / 2004$.

A lei é recente e é preciso acompanha-la de perto. Ocorre que, preliminarmente, os indícios não são de uma legislação elaborada para pautar estratégias de desenvolvimento voltadas para o Amapá, com todas as suas interfaces socioambientais.

O Amapá, desde quando se tornou unidade federativa, no início da década de 90, vem buscando traçar caminhos para o seu desenvolvimento. Os desafios são muitos. Há um grande celeiro natural de pesca, minério, madeira, frutas, produtos florestais, madeireiros e não madeireiros que não se reverte como matéria-prima em prol do desenvolvimento. É um estado rico em biodiversidade, mas pobre em sua economia, que representa $\mathrm{R} \$ 10,4$ bilhões, apenas $0,22 \%$ do PIB brasileiro (AMAPÁ, 2015).

Neste estudo, valemos de dois saberes científicos que poderiam ter sido aplicados para pensar a lei de inovação do Estado, sejam eles: legisprudência e legística. De maneira geral, esses saberes evoluíram a partir de algumas das questões recorrentes na história do direito: a) a necessidade de uma legislação mais eficaz (no sentido de estar disponível e atuante para a produção de efeitos); b) o questionamento da lei como o instrumento exclusivo para a consecução de mudanças sociais; c) a necessidade de democratizar o acesso aos textos legais em todos os níveis (SOARES, 2007).

A ideia seria utilizar a legisprudência como substrato filosófico da problematização do impulso legislativo (WINTGENS, 2012; 2013) e a legística como meio de operacionalização da razão prática ao processo legislativo, buscando uma lei mais eficiente e evitando efeitos danosos causados pela legislação mal concebida, reforçando a produção do direito consensual, concertada, que antecipa os efeitos sobre os destinatários/interessados e, desse modo, matiza o conceito do que venha a ser uma boa legislação e defendendo a atuação legislativa e regulamentar baseada nos princípios da necessidade (consideração da real necessidade de uma norma), proporcionalidade (equilíbrio entre as vantagens e as limitações/obrigações que são impostas aos cidadãos), subsidiariedade (nível de adoção da legislação), transparência (acesso aos trabalhos preparatórios), responsabilidade (determinação dos efeitos da norma, monitoramento da execução da norma), inteligibilidade, 
acessibilidade e simplicidade (publicação compreensível, consistente e acessível aos cidadãos) (ALMEIDA, 2007).

Seguindo essa linha, para pensar uma lei de inovação, seria necessário, preliminarmente, realizar um levantamento de fontes (leis estaduais) que deveriam municiar o legislador de todo o arcabouço vigente que guardaria relação com a matéria (CT\&I), vide a Lei estadual de Biodiversidade, Lei no 0388/1997. Por certo, várias normas poderiam ter sido alteradas, outras teriam conteúdo revogado, e este levantamento prepararia o cenário para a elaboração da nova lei.

O Amapá tem uma vocação socioambiental muito forte e, sim, este fato precisaria ter sido considerado mais fortemente e a criação de incentivos fiscais para a área de CT\&I deveria articular-se dentro dessa lógica, a exemplo da isenção sobre o Imposto sobre Produtos Industrializados (IPI) decorrente da Zona Franca Verde de Macapá e Santana, respectivamente, capital e município amapaenses, prevista na Lei ${ }^{\circ} 11.898 / 2009$.

Dada a temática, CT\&I, o labor sobre a lei deveria ter sido capitaneado por um grupo de trabalho multidisciplinar. A equipe deveria ter contemplado a maior diversidade de profissionais possível, atentando para o modelo da hélice tripla de inovação (Governo, Universidades e Empresas), não bastando a atuação de juristas ou de técnicos mais afeitos ao tema, e respeitando as peculiaridades do estado. Com um grupo articulado dessa maneira o diálogo entre as diferentes visões estaria garantido, dando espaço para a criatividade.

Isso porque a inovação se projeta, igualmente, no conhecimento gerado na/pela universidade, interagindo com as perspectivas de desenvolvimento das empresas e recebendo recursos de fomento por meio de políticas públicas promovidas pelo Estado (ENGELMANN, 2010).

A relação entre texto e contexto no tocante à lei amapaense de ciência, tecnologia e inovação não nos parece ter sido pensada adequadamente. Tão pouco nos parece que tenha sido garantido amplamente o contraditório e a transparência no labor pré-legislativo, a ausência de esclarecimentos sobre os resultados da chamada pública e das reuniões com o setor produtivo demonstram o prejuízo inclusive para o mapeamento dos atores de CT\&I alcançados pela nova lei. Uma trajetória sem informação qualificada, diálogo amplo e acessível, prestação de contas, publicidade e transparência por certo desconsiderou vozes.

Frise-se que essa relação, texto - contexto, no momento de elaboração legislativa é relevante, especialmente, quando se trata de um sistema normativo com grande força cogente, 
forte intervenção na liberdade, alta atividade de densificação normativa e com forte conteúdo técnico (SOARES, 2012).

\section{CONCLUSÃO}

As leis são motores para a consecução de políticas públicas e braços da implementação de programas. Leis de qualidade tornam-se pré-requisito indispensável para o desenvolvimento. Com esse destaque, resta claro que é preciso considerar a forma como os operadores conceberam e concebem as leis e atuaram e atuam para lhe dar concretude cotidiana.

O momento é mais que oportuno para pensar em novas leis de inovação e mais oportuno ainda para reabrir o debate acerca das leis já vigentes. Isso porque inovações legislativas recentes trouxeram alterações importantes para o tratamento das políticas de CT\&I, como: Emenda Constitucional no 85/2015, a Lei no 13.123/2015 (que dispõe sobre o acesso ao patrimônio genético, sobre a proteção e o acesso ao conhecimento tradicional associado e sobre a repartição de benefícios para conservação e uso sustentável da biodiversidade e que revogou a Medida Provisória no 2186-16/2001) e a Lei no 13.243/2016: novo marco legal de ciência, tecnologia e inovação.

O estado do Amapá perdeu uma excelente oportunidade de elaborar criteriosamente sua lei de inovação. O imbróglio legislativo e institucional vivenciado no caso do Contrato da Natura Inovação e Tecnologia de Produtos Ltda. com a COMARU e a BIORIO, respectivamente cooperativa e associação da Comunidade da RDS do Rio Iratapuru-AP, deveria ter servido de lição para impulsos legiferantes mais diligentes. Infelizmente, não foi o caso.

A Lei $n^{\circ} 2.333 / 2018$ nasceu a partir de um simulacro de chamada pública e em um curto espaço de tempo demandará revisão, ou pior entrará para a estatística das leis que não pegaram porque não foi fruto de uma elaboração qualificada, de um debate plural.

A leitura dos 45 (quarenta e cinco) artigos da lei não reflete o contexto amapaense, não demonstra uma preocupação com um sistema de inovação estadual que valorize a vocação socioambiental e aponte para um trabalho conjunto entre os atores de CT\&I rumo a um projeto de desenvolvimento sustentável norteado pela inovação. Evidencia a tensão entre positividade e validade discursiva, sugerindo uma necessidade de releitura dos processos 
públicos de tomada de decisão acerca da elaboração legislativa. Atesta o fato de que o estado não aprendeu com a sua própria história, suportando a carga de uma legislação que não reconheceu a pluralidade de identidades amapaenses e seus respectivos potenciais para inovação aliada à conhecimentos tradicionais.

\section{REFERÊNCIAS}

ALMEIDA, Marta Tavares de. A contribuição da legística para uma política de legislação: concepções, métodos e técnicas. In: CONGRESSO INTERNACIONAL DE LEGÍSTICA: Qualidade da Lei e Desenvolvimento (2007: Belo Horizonte, MG). Legística: qualidade da lei e desenvolvimento. Belo Horizonte: Assembleia Legislativa do Estado de Minas Gerais, 2009. p. 83-102.

AMAPÁ. Secretaria de Estado do Planejamento. Plano Plurianual 2016-2019. Macapá: SEPLAN, 2015. 45p. 1 v. Disponível em:

<http://editor.ap.gov.br/editor/Arquivos/Texto/Gestorac18c4fc0e60a3a4fff74ca4adc6d20c.pdf >. Acesso em: 20 fev. 2016.

AMAPÁ ECO CAMPING. RDS do Rio Iratapuru. Disponível em: <https://www.amapaecocamping.com/rds-do-rio-iratapuru>. Acesso em: 10 jan. 2017.

AMAPÁ. Lei $n^{o}$ 2.333, de 25 de abril de 2018. Dispõe sobre indução e incentivos ao desenvolvimento do Sistema de Ciência, Tecnologia e Inovação, por meio de instrumentos que concedem suporte ao desenvolvimento do ambiente produtivo no Estado do Amapá e dá outras providências. Publicada no Diário Oficial do Estado nº 6668, de 25.04.2018. Disponível em:

<http://www.al.ap.gov.br/pagina.php?pg=buscar_legislacao\&n_leiB=2333,\%20de\%2025/04/ 18>. Acesso em: 10 maio de 2018.

ASSUNÇÃO, Linara Oeiras. Legislação, Desenvolvimento e Inovação: Caminhos metodológicos para a elaboração de marcos legais propulsores de desenvolvimento com inovação. 2017. 287 f. Tese (Doutorado) - Faculdade de Direito, Universidade Federal de Minas Gerais, Belo Horizonte, 2018.

BASSALO, Gisa. Importância da Lei Paraense de Inovação. Revista de Ciência, Tecnologia e Inovação do Estado do Pará. Ver-a-Ciência. Ano 1, no 1, jun. 2012, p. 24-27. Disponível em: <http://www.veraciencia.pa.gov.br/upload/arq_arquivo/60.pdf>. Acesso em: 12 jan. 2017.

COSTA, Jesse James Lima da. Primeiro Contrato de Acesso aos Recursos da Biodiversidade do Estado do Amapá. Conferência Regional de CT\&I. 29, 30 de junho e 01 de julho de 2007. Manaus-AM. Disponível em: <http://www.ceap.br/material/MAT21102009160727.pdf>. Acesso em: 11 jan. 2017.

COUTINHO, Diogo R.; MOUALLEM, Pedro S. B. Gargalos jurídico-institucionais à 
inovação no Brasil. In: COUTINHO, Diogo R.; ROCHA, Jean-Paul Veiga da; SCHAPIRO, Mario G. (Coords.). Direito Econômico Atual. São Paulo: Editora Método, 2015, p. 86-119.

DIÁRIO DO AMAPÁ. Governo do Amapá lança minuta do Marco Legal da Ciência, Tecnologia e Inovação. 24 de novembro de 2017. Disponível em:

<https://www.diariodoamapa.com.br/cadernos/politica/governo-do-amapa-lanca-minuta-domarco-legal-da-ciencia-tecnologia-e-inovacao/>. Acesso em: 26 nov. 2017.

EM DISCUSSÃO! Leis Estaduais beneficiam inovação. Revista de audiências públicas do Senado Federal, Ano 3, n. 12, set. 2012, p. 48-49. Disponível em:

<http://www.senado.gov.br/NOTICIAS/JORNAL/EMDISCUSSAO/upload/201203\%20$\% 20$ setembro/pdf/em\%20discuss\%C3\%A3o!_setembro_2012_internet.pdf $>$. Acesso em: 06 dez. 2016.

ENGELMANN, Wilson. As nanotecnologias e a inovação tecnológica: a "hélice quádrupla" e os direitos humanos. Blog JUSNANO, São Leopoldo, 2010. Disponível em:

http://jusnano.blogspot.com.br. Acesso: 10 abr. 2015.

GRIZENDI, Eduardo. Manual de Orientações Gerais sobre Inovação. Ministério das Relações Exteriores. Departamento de Promoção Comercial e Investimentos. Divisão de Programas de Promoção Comercial. 2011. Disponível em:

<http://www.investexportbrasil.gov.br/sites/default/files/publicacoes/estudos/PUBEstudosMa nualDaInovacao.pdf>. Acesso em: 10 jan. 2017.

INSTITUTO BRASILEIRO DE GEOGRAFIA E ESTATÍSTICA (IBGE). Pesquisa de Inovação Tecnológica (PINTEC). Coordenação de Indústria. Rio de Janeiro: IBGE, 2016.

MINISTÉRIO DE CIÊNCIA, TECNOLOGIA, INOVAÇÕES E COMUNICAÇÕES (MCTIC); CONSELHO NACIONAL DAS FUNDAÇÕES DE APOIO ÀS INSTITUIÇÕES DE ENSINO SUPERIOR E DE PESQUISA CIENTIIFICA E TECNOLÓGICA (CONFIES (MCTI). Estratégia Nacional de Ciência, Tecnologia e Inovação 2016-2019. Brasília, 2016. Disponível em:

<http://www.mcti.gov.br/documents/10179/1712401/Estrat\%C3\%A9gia+Nacional+de+Ci\%C 3\%AAncia\%2C\%20Tecnologia+e+Inova\%C3\% A7\%C3\%A3o+2016-2019/0cfb61e1-1b844323-b136-8c3a5f2a4bb7>. Acesso em: 20 set. 2016.

PLAZA, Charlene Maria C. de Ávila. Análises das leis estaduais de inovação tecnológica de São Paulo, Minas Gerais, Santa Catarina, Mato Grosso e Amazonas e seus respectivos contratos. In: BARBOSA, Dênis B. Direito da Inovação. Rio de Janeiro: Lumen Juris, 2011.

PORTAL GOVERNO DO AMAPÁ. Cidadão pode ajudar a elaborar Marco Legal da Ciência e Tecnologia do Amapá até fevereiro. 15 de janeiro de 2018. Disponível em: $<$ https://www.portal.ap.gov.br/noticia/1501/cidadao-pode-ajudar-a-elaborar-marco-legal-daciencia-e-tecnologia-do-amapa-ate-fevereiro>. Acesso em: 16 jan. 2018.

RIBEIRO, Magda dos Santos. Ouriços e embalagens: Castanheiros, empresários e as economias de suas relações. $40^{\circ}$ Encontro Anual Anpocs, 24 a 28 de outubro de 2016. 
Caxambu-MG. Disponível em: <http://www.anpocs.com/index.php/papers-40-encontro/spg3/spg23-2/10090-ouricos-e-embalagens-castanheiros-empresarios-e-as-economias-de-suasrelacoes/file>. Acesso em: 05 jan. 2017.

SANTOS, Marcelo Moreira dos. Direito ao Patrimônio Genético: acesso e repartição de benefícios em Iratapuru. Dissertação do Mestrado Integrado em Desenvolvimento Regional, UNIFAP, Macapá, 2008.

SOARES, Fabiana de Menezes. Legística e Desenvolvimento: a qualidade da lei no quadro da otimização de uma melhor legislação. Revista da Faculdade de Direito da UFMG. n. 50. Jan. - Jul., 2007, p. 124-142.

SOARES, Fabiana de Menezes. Simplificação e elaboração da legislação tributária infralegal: notas sobre o acesso ao direito vigente e a gestão da elaboração legislativa pelo Executivo. Caderno de Finanças Públicas. Escola de Administração Fazendária. n. 12. Dez. 2012. Brasília: ESAF, 2012.

TANURE, Betania; PATRUS, Roberto. Natura, a realização de um sonho. São Paulo: Editora Elsevier, 2011.

VERZOLA, Sabrina Carvalho. A lei de inovação e a proteção do conhecimento tradicional. Fragmentos de Cultura, Goiânia, v. 25, n. 2, p. 185-192, abr./jun. 2015. Disponível em: <http://seer.ucg.br/index.php/fragmentos/article/download/4180/2392>. Acesso em: 12 jan. 2017.

WINTGENS, Luc Jean. Legisprudence: Practical Reason in Legislation. Farnham: Ashgate, 2012.

WINTGENS, Luc Jean; OLIVER-LANANA, A. Daniel (Orgs.). The Rationalitty and Justification of Legislation. Essays in Legisprudence. Legisprudence Library 1. Switzerland: Springer, 2013.

WWF BRASIL. Reserva do Iratapuru antenada com o mundo, 6 de agosto de 2010. Disponível em: <http://www.wwf.org.br/informacoes/?25700/Reserva-do-Iratapuru-antenadacom-o-mundo>. Acesso em: 10 jan. 2017. 